\title{
Suppression of Ras-stimulated transformation by the JNK signal transduction pathway
}

\author{
Norman J. Kennedy, ${ }^{1}$ Hayla K. Sluss, ${ }^{2}$ Stephen N. Jones, ${ }^{2}$ Dafna Bar-Sagi, ${ }^{3}$ Richard A. Flavell, ${ }^{4}$ and \\ Roger J. Davis ${ }^{1,5}$ \\ ${ }^{1}$ Howard Hughes Medical Institute, and Program in Molecular Medicine, University of Massachusetts Medical School, \\ Worcester, Massachusetts 01605, USA; ${ }^{2}$ Department of Cell Biology, University of Massachusetts Medical School, \\ Worcester, Massachusetts 01605, USA; ${ }^{3}$ Department of Molecular Genetics and Microbiology, State University of New York \\ at Stony Brook, Stony Brook, New York 11794, USA; ${ }^{4}$ Howard Hughes Medical Institute, Section of Immunobiology, Yale \\ University School of Medicine, New Haven, Connecticut 06520, USA
}

The c-Jun $\mathrm{NH}_{2}$-terminal kinase (JNK) phosphorylates and activates members of the activator protein-1 (AP-1) group of transcription factors and is implicated in oncogenic transformation. To examine the role of JNK, we investigated the effect of JNK deficiency on Ras-stimulated transformation. We demonstrate that although JNK does play a role in transformation in vitro, JNK is not required for tumor development in vivo. Importantly, the loss of JNK expression resulted in substantial increases in the number and growth of tumor nodules in vivo. Complementation assays demonstrated that this phenotype was caused by JNK deficiency. These data demonstrate that, in contrast to expectations, the normal function of JNK may be to suppress tumor development in vivo. This conclusion is consistent with the presence in human tumors of loss-of-function mutations in the JNK pathway.

[Keywords: JNK; Ras; tumor suppressor; cancer; apoptosis; MAP kinase]

Received November 27, 2002; revised version accepted January 14, 2003.

Surface receptors bound by mitogenic factors transduce signals through a variety of intracellular pathways that converge on the nucleus to alter gene expression in favor of cell growth. Cellular transformation and tumor development can be the outcome of a dysregulated response to mitogenic signals. A key signaling molecule in many types of tumors is the small GTP-binding protein Ras. Indeed, constitutively active forms of Ras that induce cellular transformation have been identified in many human cancers (Bos 1989).

Several signal transduction pathways mediate the tumorigenic potential of oncogenic Ras. Included among these pathways are the mitogen-activated protein (MAP) kinase signaling cascades. While best known for its ability to induce the extracellular signal-regulated kinase (ERK) pathway, Ras also activates the c-Jun $\mathrm{NH}_{2}$-terminal kinase (JNK) MAP kinase signaling cascade leading to phosphorylation of c-Jun and augmentation of AP-1 transcriptional activity (Davis 2000). Interestingly, c-Jun is required for Ras-induced transformation (Johnson et al. 1996). In addition, transformation by Ras is inhibited by mutation of the JNK phosphorylation sites on c-Jun

${ }^{5}$ Corresponding author.

E-MAIL Roger.Davis@Umassmed.Edu; FAX (508) 856-3210.

Article published online ahead of print. Article and publication date are at http://www.genesdev.org/cgi/doi/10.1101/gad.1062903.
(Behrens et al. 2000). Moreover, several loss-of-function studies indicate that JNK is required for transformation (Davis 2000); for example, studies using antisense oligonucleotides demonstrate that JNK inhibition can cause growth arrest or apoptosis of some tumor cells (Potapova et al. 1997, 2000; Bost et al. 1999). Together, these studies indicate that JNK may be essential for tumor development. However, a direct test of this prediction has not been reported.

Recent studies of human tumors indicate the presence of inactivating mutations in JNK (Yoshida et al. 2001) and MKK4 (Teng et al. 1997; Su et al. 1998, 2002), a MAP kinase kinase that phosphorylates and activates JNK (Davis 2000). Intriguingly, these mutations in human tumors correlate with increased tumor grade and metastasis (Yoshida et al. 1999; Wu et al. 2000; Debies and Welch 2001; Kim et al. 2001; Yamada et al. 2002). It is unclear whether these human tumor-associated mutations are a cause or an effect of the increased tumor grade. Nevertheless, these observations suggest that the JNK pathway may act to suppress tumor development. This conclusion markedly contrasts with conclusions drawn from the results of other studies that suggest an essential role for JNK in tumor development. Consequently, the role of JNK in tumor development is unclear. 
Kennedy et al.

The purpose of the present study was to examine the role of JNK in cell transformation by investigating the effect of targeted disruptions of the murine Ink genes on Ras-stimulated transformation. We show that JNK deficiency causes profound increases in the number and growth of Ras-induced tumor nodules in vivo. Thus, the JNK signaling pathway functions to suppress the oncogenic effects of Ras.

\section{Results}

Compound mutations that disrupt the expression of the ubiquitously expressed genes $I n k 1$ and $I n k 2$ cause early embryonic lethality in mice (Kuan et al. 1999; Sabapathy et al. 1999). Consequently, tumor studies in JNK-deficient mice are not feasible. We therefore employed an alternative strategy to investigate the effect of JNK deficiency on Ras-stimulated transformation. Our approach was to compare fibroblasts derived from wild-type and Ink $1^{-/-}$Ink2 $2^{-/-}$mice (Tournier et al. 2000). Primary fibroblasts were established in culture using the $3 \mathrm{~T} 3$ protocol and transduced with a retroviral vector that ex- presses activated Ras (Leu-61) or with an empty vector (Control). Pools of at least 100 independent clones were employed for further analysis. The increased expression of Ras was detected by immunoblot analysis (Fig. 1B). Ras caused a fourfold increase in JNK activity in wildtype cells. In contrast, the $/ n k 1^{-/-} / n k 2^{-/-}$(Jnk-null) cells lacked detectable JNK protein and activity (Fig. 1A). Control studies demonstrated that Ras activated the ERK and p38 MAP kinases to a similar extent in the wild-type and Ink-null cells (Fig. 1A). Similarly, no difference in the effect of Ras to induce p53-independent expression of $p 21$ (Macleod et al. 1995) was detected between wild-type and Ink-null cells (Fig. 1B).

It was established in previous studies that fibroblast immortalization is associated with functional inactivation of the p53 tumor suppressor pathway mediated, in part, by loss of ARF or by mutational inactivation of p53 (Sherr and DePinho 2000). Because p53 inactivation is critical for some forms of tumor development (Vogelstein et al. 2000), we examined the status of the p53 pathway in the wild-type and Jnk-null cells by examining 53-mediated growth arrest caused by ionizing radia-
A
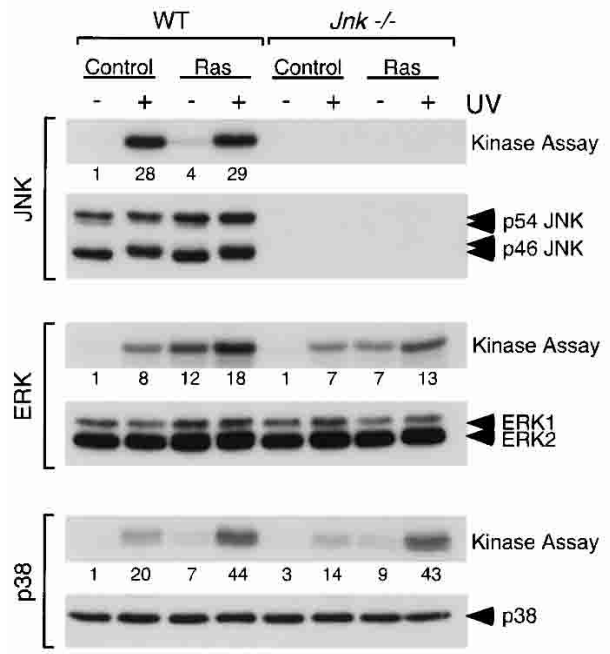

B

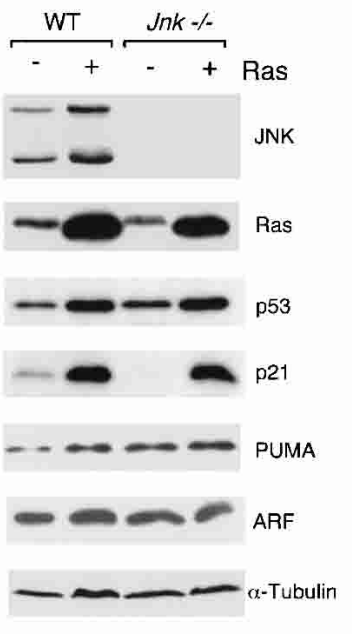

C

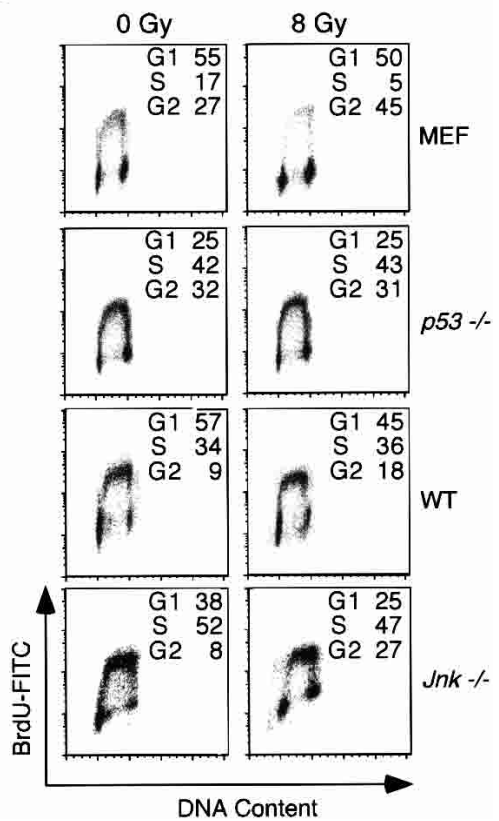

Figure 1. Characterization of wild-type and Ink-null fibroblasts. (A) Wild-type (WT) and Ink-null cells were transduced with a retrovirus vector that expresses activated Ras (Leu-61) or with the empty vector (Control). The cells obtained were pools of at least 100 individual clones. MAP kinase activity was examined by in vitro protein kinase assays using the substrate c-Jun, MBP, and ATF2 for JNK, ERK, and p38, respectively. The cells were exposed in the absence or presence of $60 \mathrm{~J} / \mathrm{m}^{2} \mathrm{UV}-\mathrm{C}$ radiation $45 \mathrm{~min}$ prior to harvesting. The protein kinase activity was detected by autoradiography and was quantitated by PhosphorImager analysis (the relative activity is indicated below the autoradiograph). The expression of MAP kinases was examined by immunoblot analysis. $(B)$ The fibroblasts were examined by immunoblot analysis of cell lysates for the expression of JNK, p53, p21, PUMA, ARF, and $\alpha$-tubulin. Activated Ras was isolated from the lysates by incubation with Raf beads (Upstate Biotechnology), and the bound (activated) Ras was detected by immunoblot analysis. The level of total Ras detected by immunoblot analysis of lysates was approximately twofold greater in Ras-transformed cells than in the nontransformed cells (data not shown). (C) Wild-type and p53 ${ }^{-/-}$primary murine embryo fibroblasts (MEF) and wild-type and Ink-null immortalized fibroblasts were exposed to ionizing radiation (8 Gy). The cells were incubated $(15 \mathrm{~h})$ and then pulse-labeled by incubation with $10 \mu \mathrm{M} \operatorname{BrdU}(3 \mathrm{~h})$. DNA content and BrdU incorporation were examined by flow cytometry. 
tion (IR). Exposure to IR caused loss of DNA synthesis by wild-type primary fibroblasts, but not by $p 53^{-/-}$primary fibroblasts or by the immortalized wild-type or Jnk-null fibroblasts (Fig. 1C). These data establish that both the wild-type and Ink-null fibroblasts employed in this study lack a functional p53 pathway. Indeed, no marked differences in the expression of the p53-dependent gene Puma (Nakano and Vousden 2001; Yu et al. 2001) were detected between Ras-transformed wild-type and Ink-null cells (Fig. 1B). Loss of ARF expression did not appear to contribute to the inactivation of $\mathrm{p} 53$, because both ARF and p53 were detected by immunoblot analysis (Fig. 1B). Sequence analysis of cDNA isolated from wild-type and Jnk-null cells indicated the presence of inactivating p53 mutations. Together, these data demonstrate that both the wild-type and the Ink-null fibroblasts have a functionally inactivated p53 pathway.

Expression of oncogenes is often associated with increased levels of apoptosis (Evan and Vousden 2001). For example, Ras can cause p53-independent apoptosis of target cells (Joneson and Bar-Sagi 1999). The JNK signaling pathway is required for apoptosis in response to the exposure of cells to some forms of stress (Tournier et al. 2000). Whether JNK is required for oncogene-stimulated apoptosis is unclear. We therefore examined apoptosis of wild-type and Ink-null cells. A low level of apoptosis was detected in proliferating cultures of wild-type and Inknull cells by measurement of DNA fragmentation (Fig. 2A). Ras caused a marked increase in apoptosis of wildtype cells, but not Ink-null cells (Fig. 2A). Control studies were performed by exposure of the cells to a strong apoptotic stimulus, ultraviolet light (UV-C), which caused increased apoptosis of wild-type cells and poten- tiated the apoptotic effects of Ras. In contrast, the Inknull cells were resistant to the effects of both UV-C and Ras (Fig. 2A). The ability of JNK deficiency to suppress Ras-induced apoptosis was confirmed by measurement of the number of cells with activated caspase (Fig. 2B). These data indicate that the absence of JNK suppresses the apoptotic response of cells to Ras. However, fibroblasts lacking a functional JNK pathway are as sensitive as wild-type cells to death induced by c-Myc (Fig. 2C). Thus, Ink-null fibroblasts display selective apoptotic resistance to oncogenic stimuli. The observed defect in Ras-stimulated apoptosis may contribute to the effects of JNK deficiency on transformation.

We performed initial studies to test the effect of JNK deficiency on Ras-induced transformation using in vitro studies. Morphological examination demonstrated that the wild-type and Ink-null cells displayed the typical flat appearance of nontransformed cells (Fig. 3A). Ras caused changes indicative of transformation in wild-type cells, including a rounded and refractile morphology (Fig. 3A). These changes were markedly reduced in the Ink-null cells, which adopted a more elongated and flattened, less light-refractive, spindle shape (Fig. 3A). Complementation analysis demonstrated that the expression of JNK1, but not JNK2, partially restored the Ras-induced morphological changes in the Jnk-null cells. JNK may therefore contribute to the physical changes in cell shape caused by activated Ras. Both wild-type and Ink-null cells arrested when grown to confluence and formed monolayers (Fig. 3B), although the saturation density of the Ink-null cells was greater than that of the wild-type cells (Fig. 3B,C). This contact growth inhibition was absent in both wild-type and Jnk-null cells transformed by
A

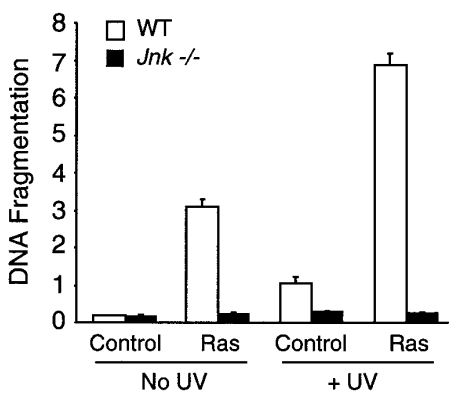

B

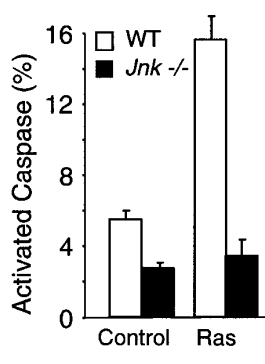

C

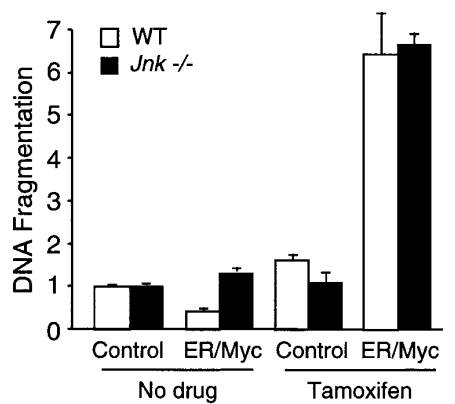

Figure 2. JNK is required for Ras-stimulated apoptosis in vitro. (A) Nucleosomal fragmentation of chromosomal DNA was examined in cultures of exponentially growing wild-type and Ink-null fibroblasts. Some cultures were exposed to $60 \mathrm{~J} / \mathrm{m}^{2} \mathrm{UV}-\mathrm{C}$ radiation $16 \mathrm{~h}$ prior to harvesting. The data are presented as the normalized mean optical density $(O D) \pm S . D$. $(n=3)$. The data presented are representative of three independent experiments. The UV-stimulated apoptosis of wild-type 3T3 cells is reduced compared with the robust response of wild-type primary murine embryo fibroblasts (MEF). However, both Ink-null MEF (Tournier et al. 2000) and Ink-null 3 T3 cells (the present study) are resistant to UV-C-stimulated apoptosis. (B) The number of cells with activated caspase was measured in cultures of wild-type and Ink-null fibroblasts. The effect of Ras transformation was examined. The data are presented as the percent of total cells with activated caspases \pm S.D. $(n=3)$. $(C)$ Wild-type and Ink-null fibroblasts were transduced with a bicistronic retrovirus that expresses GFP and an estrogen receptor/c-Myc (ER/Myc) fusion protein. c-Myc-dependent apoptosis was examined by incubation $(24 \mathrm{~h})$ of the cells with $1 \mu \mathrm{M}$ 4-hydroxytamoxifen (Tamoxifen) in serum-free media. Nucleosomal fragmentation of chromosomal DNA was examined. The data are presented as the normalized mean $\mathrm{OD} \pm$ S.D. $(n=3)$. The data presented are representative of three independent experiments. The basal level of apoptosis observed in serum-free medium $(C)$ was greater than the basal apoptosis detected in the presence of serum $(A)$. 
Kennedy et al.

A
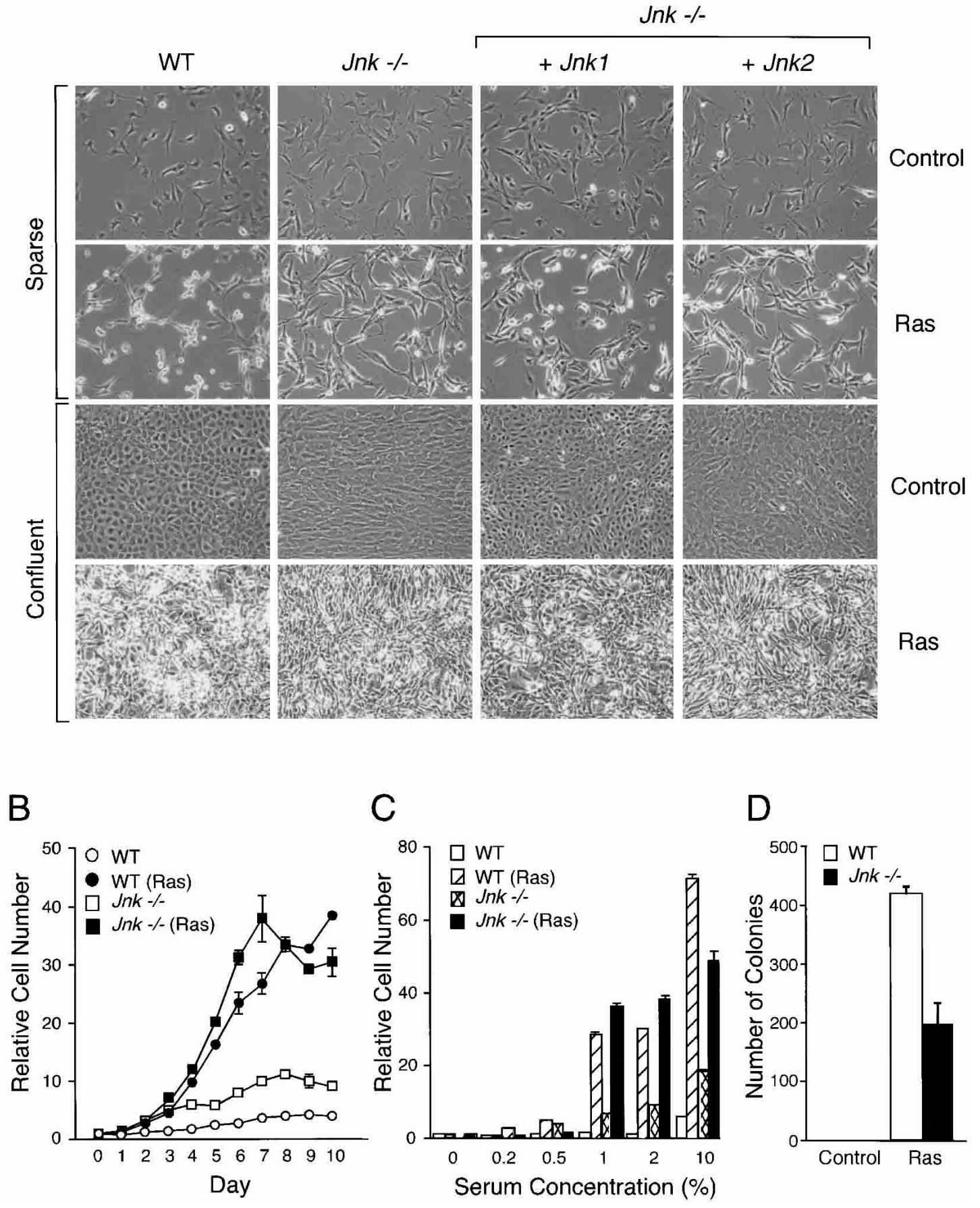

D

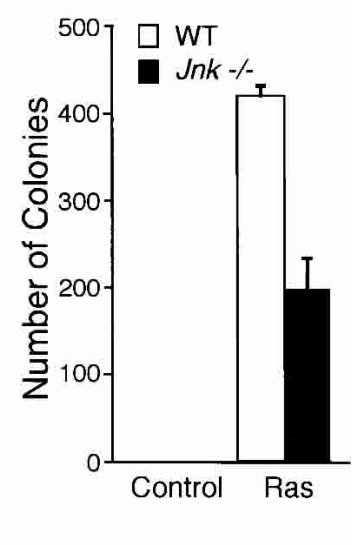

Figure 3. Analysis of wild-type and Ink-null fibroblasts transformed with Ras in vitro. (A) Cell morphology in sparse and confluent cultures was examined by phase contrast microscopy. The morphology of wild-type cells, Ink-null cells, and Ink-null cells complemented with Ink1 or Jnk2 is shown. $(B)$ Cell proliferation in medium supplemented with $10 \%$ fetal calf serum was examined by crystal violet staining (mean OD at $590 \mathrm{~nm} \pm$ S.D.; $\mathrm{n}=3$ ) following the addition of $1 \times 10^{4}$ cells to $20-\mathrm{mm}$ tissue culture dishes. The data are expressed as relative cell number. $(C)$ The saturation growth density in different concentrations of serum was examined by crystal violet staining (mean OD at $590 \mathrm{~nm} \pm$ S.D.; $\mathrm{n}=3$ ). Relative cell numbers were measured at day $0(\mathrm{D}=0)$ and after culture for $10 \mathrm{~d}$ $(\mathrm{D}=10)$. (D) Wild-type and Ink-null fibroblasts were plated in soft agar, then incubated for $14 \mathrm{~d}$, and the number of colonies was measured. The data presented are the mean \pm S.D. of triplicate data obtained in three independent experiments.

Ras, which formed multiple layers in culture (Fig. 3A), and grew to a higher saturation density than the non- transformed cells (Fig. 3C). The proliferation of the Rastransformed Jnk-null cells was slightly greater than that 
of the wild-type cells (Fig. 3C), consistent with the observed reduction in apoptosis (Fig. 2B,C) and increased DNA synthesis (Fig. 1C). Ras caused a similar increase in proliferation of wild-type and Ink-null cells cultured in low serum (Fig. 3C). In contrast, JNK deficiency caused a small (twofold) decrease in the number of anchorage-independent colonies that grew in soft agar (Fig. 3D). Together, these data demonstrate that JNK is not required for the dysregulated control of proliferation caused by Ras, including loss of contact growth inhibition and growth in low concentrations of serum. However, JNK deficiency does partially impair anchorage-independent growth in vitro and appears to be required for the normal effects of Ras on cellular morphology.

We tested the tumorigenic potential of wild-type and Jnk-null cells in vivo by subcutaneous injection of the cells into athymic nude mice. Control cells without Ras did not form tumors. However, subcutaneous tumors were detected in all mice injected with Ras-transformed wild-type or Ink-null cells (data not shown). These data demonstrate that JNK is not essential for tumor development in vivo. This observation is consistent with the finding that JNK deficiency causes only partial defects in the effects of Ras in studies of these cells in vitro (Fig. 3). To examine further the effect of JNK deficiency on tumor development in vivo, we investigated the formation of lung tumors in a model of tumor metastasis. No tumor nodules were detected in mice with control cells without Ras. However, tumor nodules were found in mice with Ras-transformed cells (Fig. 4A). Strikingly, the lungs of mice with Ras-transformed Ink-null cells contained a substantially greater tumor mass compared to mice with Ras-transformed wild-type cells (Fig. 4A). To test whether this increased tumor burden was caused by JNK deficiency, we performed complementation experiments using JNK1 or JNK2. Immunoblot analysis confirmed the expression of JNK (Fig. 4B), and analysis of tumors in vivo indicated that the expression of JNK1 or JNK2 complemented the effect of JNK deficiency to increase lung tumor mass (Fig. 4C). These data demonstrate that the absence of JNK caused increased Rasstimulated tumorigenesis in vivo. The increased tumor burden could be caused by an increase in the number or the size of the lung tumor nodules. To distinguish between these possibilities, we performed titration experiments using different numbers of tumor cells (Fig. 4D). These data demonstrated that Ras-transformed Ink-null cells caused a larger number of lung tumor nodules (Fig. $4 \mathrm{E}$ ) and that the size of the individual tumor nodules was also larger (Fig. 4F).

Histological analysis did not reveal marked differences between the wild-type and Ink-null tumor nodules (Fig. 4G). In addition, similar proliferation of wild-type and Jnk-null tumor cells was detected by immunocytochemical analysis of BrdU incorporation in vivo (Fig. 4G). Furthermore, staining of the endothelial cell marker PECAM-1 indicated no marked differences in angiogenesis. However, whereas wild-type tumors were found to contain many apoptotic cells, very few apoptotic cells were detected in the Ink-null tumors (Fig. 4G). This severe reduction in cell death in vivo (Fig. 4G) is consistent with the results of apoptosis assays in vitro (Fig. 2A,B) and may contribute to the increased tumor burden caused by JNK deficiency (Fig. 4A).

\section{Discussion}

The results of this study indicate that JNK may be required for some aspects of Ras-transformation in vitro, including cellular morphology (Fig. 3A), anchorage-independent growth (Fig. 3D), and Ras-stimulated apoptosis (Fig. 2A,B). Other characteristics of Ras-transformed cells in vitro do not appear to require JNK, including loss of contact growth inhibition (Fig. 3A,B) and growth in low concentrations of serum (Fig. 3C). Similarly, JNK is not required for Ras-induced tumor formation in vivo (Fig. 4). Indeed, quantitative analysis demonstrated that Ink-null fibroblasts caused a marked increase in tumor burden compared to wild-type fibroblasts (Fig. 4). Complementation assays demonstrated that this phenotype was caused by JNK deficiency (Fig. 4). Together, these data indicate that, in contrast to expectations, JNK is a negative regulator of Ras-induced tumorigenesis in vivo.

Previous studies established that suppression of apoptosis is an important aspect of tumor development (Evan and Vousden 2001). Multiple mechanisms for inhibition of apoptosis have been identified in different human tumors. Examples include increased expression of the antiapoptotic protein Bcl2 caused by a chromosomal translocation (Gross et al. 1999), inactivation of the apoptosis effectors p53 (Vogelstein et al. 2000) and Apaf-1 (Soengas et al. 2001), and inactivation of PTEN, a phosphatase that inhibits the Akt/PKB survival pathway (Datta et al. 1999; Maehama et al. 2001). Furthermore, in vitro studies have demonstrated that inactivation of apoptotic proteins potentiates cellular transformation, including members of the proapoptotic Bcl2 family (Zong et al. 2001) and caspases (Soengas et al. 1999). These observations are similar to the abilities of JNK deficiency to prevent Ras-stimulated apoptosis (Figs. $2 \mathrm{~A}, \mathrm{~B}, 4 \mathrm{D})$ and to increase tumorigenesis (Fig. 4A). The JNK signaling pathway therefore may act, in part, by an apoptotic mechanism to suppress tumor formation in vivo.

The presence of two ubiquitously expressed genes (Jnk1 and Ink2) that encode the JNK protein kinase indicates that the mutational loss of JNK expression is most likely a very-low-frequency event in normal tumor development. It is therefore unlikely that Ink1 and Ink2 function as classical tumor suppressor genes. However, Jnk3 is selectively expressed in the brain and has functions that are nonredundant with $J n k 1$ and $J n k 2$ (Yang et al. 1997b). Ink3 is a candidate tumor suppressor gene, because Ink3 was found to be disrupted in 10 of 19 human brain tumors (Yoshida et al. 2001). Similarly, the genes that encode the protein kinases that activate JNK (Mkk4 and Mkk7) serve nonredundant functions (Nishina et al. 1997; Yang et al. 1997a; Ganiatsas et al. 1998; Tournier et al. 2001) and therefore could act as tumor suppressor genes. Indeed, Mkk4 is mutated in hu- 
Kennedy et al.

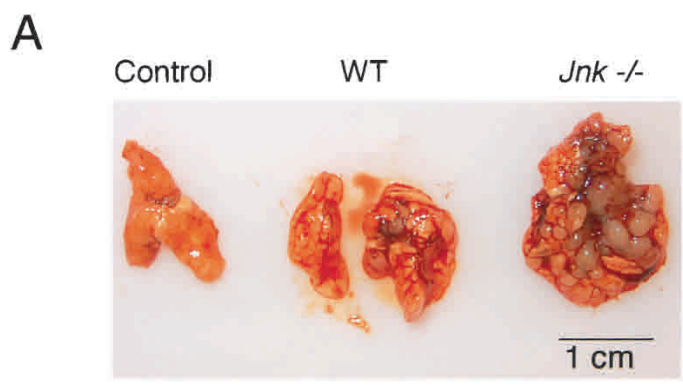

Figure 4. JNK suppresses tumor development in vivo. $(A, B)$ Wild-type and Ink-null cells $\left(5 \times 10^{5}\right)$ were injected into the tail vein of 12 -week-old male athymic nude mice (Charles River). The mice were injected with $400 \mu \mathrm{g}$ of BrdU on day 13 and euthanized on day 14. (A) Representative Ras-induced tumor nodules in the lungs are illustrated. (B) Wild-type and Ink-null cells were examined by immunoblot analysis using antibodies to JNK and $\alpha$-tubulin. Complementation assays were performed using Ink-null cells expressing Ink1 or Ink2. (C) The lung mass as a percentage of total body mass (mean \pm S.D.; $\mathrm{n}=5$ ) is presented as relative lung mass. The data presented are representative of three independent experiments. $(D-F)$ Dose-response analysis of tumor formation by Ras-transformed wild-type and Ink-null cells. The effects of injecting different numbers of transformed cells on the tumor burden $(D)$, the number of tumor nodules $(E)$, and the number of tumor nodules with a surface greater than $2 \mathrm{~mm}^{2}(F)$ are shown. The data presented represent the mean mass \pm S.D. $(\mathrm{n}=5) .(G)$ The wildtype and Ink-null tumor nodules were examined by immunocytochemistry. Representative images of sections stained with hematoxylin and eosin (H\&E), with an antibody to BrdU to detect proliferating cells, by TUNEL assay for apoptotic cells, and with an antibody to the endothelial cell protein PECAM-1.
B

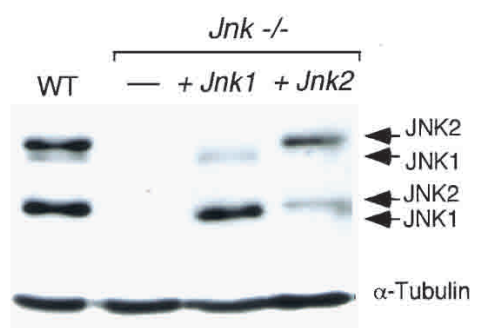

C

D

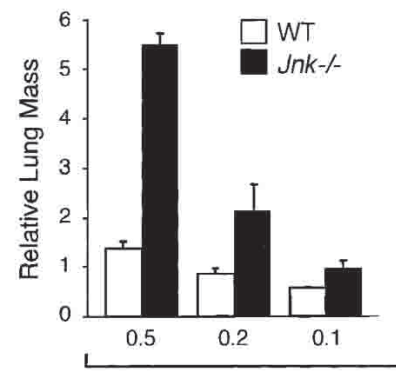

$E$

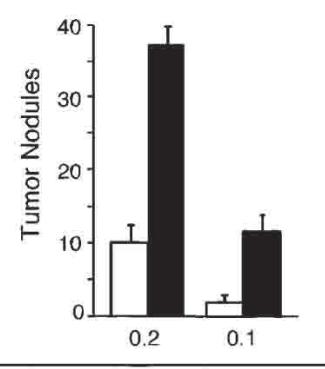

$\mathrm{F}$

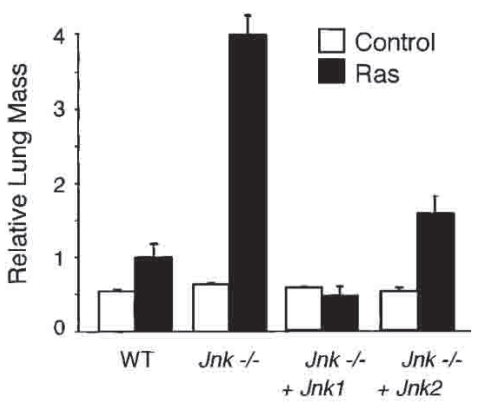

G

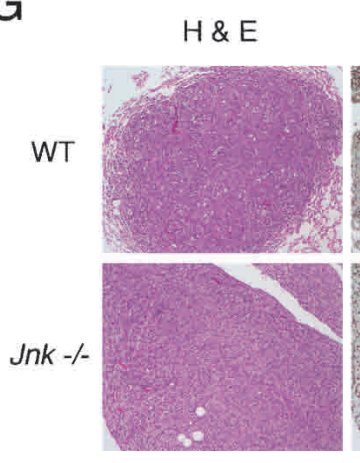

Cells Injected $\left(x 10^{6}\right)$

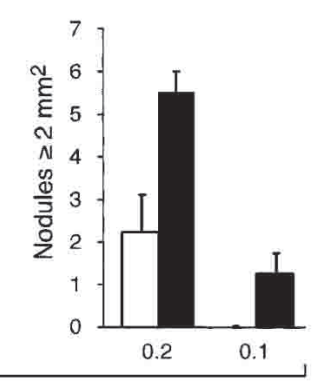

BrdU

TUNEL

PECAM-1
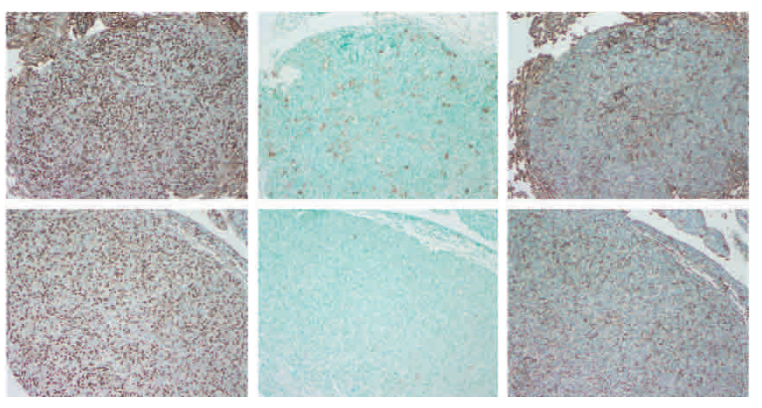

man pancreatic, lung, breast, colorectal, and prostate cancer (Teng et al. 1997; Su et al. 1998; Yoshida et al. 1999; Kim et al. 2001). Loss-of-function mutations in Mkk4 cause markedly reduced JNK activation (Nishina et al. 1997; Yang et al. 1997a; Ganiatsas et al. 1998; Tournier et al. 2001) and correlate with aggressive tumor development and metastasis (Yoshida et al. 1999; Wu et al. 2000; Debies and Welch 2001; Kim et al. 2001; Yamada et al. 2002). These observations are consistent with the results of the present study that indicate that the
JNK signaling pathway may function to suppress tumor development in vivo.

The JNK signaling pathway is activated by the exposure of cells to stress. Oncogenic transformation represents an example of stress that causes JNK activation. One cellular response to JNK activation is apoptosis, which can be mediated by the mitochondrial pathway (Tournier et al. 2000). JNK signaling may therefore function as a component of a tumor surveillance system that is activated by stress. Consequently, JNK inhibition may 
not prove to be a successful strategy for the treatment of some tumors. However, the role of JNK may be altered by the genetic background and tissue origin of the tumor. Thus, although JNK suppresses Ras-stimulated tumor formation (Fig. 4), JNK can potentiate B-cell lymphoma caused by Bcr-Abl (Hess et al. 2002). The use of smallmolecule inhibitors of JNK (Bennett et al. 2001) may therefore be appropriate for the treatment of some forms of cancer, but the results of the present study indicate that this strategy would not be a general approach for tumor therapy.

\section{Materials and methods}

\section{Mice}

Tumor assays were performed using 12-week-old male athymic nude mice (Charles River). The animals were housed in a facility accredited by the American Association for Laboratory Animal Care, and the animal studies were approved by the Institutional Animal Care and Use Committee (IACUC) of the University of Massachusetts. Wild-type and Ink-null cells were injected subcutaneously or in the tail vein (Clark et al. 1995). The mice were euthanized at 2 wk postinjection.

\section{Cell culture}

Wild-type and JNK-deficient primary embryo fibroblasts (mouse strain 129svJ) were isolated (Tournier et al. 2000) and cultured in Dulbecco's modified Eagle's medium with $10 \%$ fetal calf serum using the 3T3 protocol (Harvey et al. 1993). The established cell lines represent pools of at least 100 independent clones. The cells were transduced (Danos and Mulligan 1988) with the retroviral vectors pBABE-H-Ras(Leu-61)-IRES-Puro ${ }^{\mathrm{R}}$ (Johnson et al. 1996), pBABE-IRES-Puro ${ }^{\mathrm{R}}$ (Morgenstern and Land 1990), MSCVER/Myc-IRES-GFP, and MSCV-IRES-GFP (Zindy et al. 1998) that were packaged using Phoenix cells (Pear et al. 1993). The transduced cells were selected with $2 \mu \mathrm{g} / \mathrm{mL}$ puromycin or by flow cytometry using GFP. Studies of the transduced cells employed pools of at least $10^{5}$ independent clones, and the data presented are representative of studies using three different populations of cells that were isolated independently. Soft agar assays were performed using methods described previously (Clark et al. 1995).

\section{Biochemical assays}

The methods used for crystal violet staining, protein kinase assays, measurement of DNA fragmentation, and immunoblot analysis were described (Raingeaud et al. 1995; Tournier et al. 2000). The number of apoptotic cells was examined by incubation (12 h) of cells with FITC-VAD-fmk (1/100 dilution; Oncogene Research Products), washing the cells, staining nuclei with 4'-6'-diamino-2-phenylindole, and inspection by fluorescence microscopy (Zeiss Axiovert 200M); the apoptotic cells (FITCpositive) were scored as the percentage of the total cells. BrdU incorporation and DNA content of cells was examined by flow cytometry (Hess et al. 2002).

\section{Analysis of p53}

Total RNA ( $3 \mu \mathrm{g}$ ) was used for reverse transcriptase PCR (Invitrogen) to isolate the p53 cDNA from primary fibroblasts (wild- type and Ink-null) and 24 independent wild-type and Ink-null clones using the primers CAGTTCATTGGGACCATCCT (exon1 Forward) and AGGATTGTGTCTCAGCCCTG (exon 11 Reverse). The p53 cDNA was sequenced using an Applied Biosystems machine. No mutations were detected in the sequence of p53 from primary fibroblasts (wild-type and Ink-null). In contrast, sequence analysis of 24 independent wild-type and 24 independent Ink-null 3T3 cell clones demonstrated the presence of p53 mutations.

\section{Histology}

Tissue was fixed and processed for histological analysis. Sections were stained with hematoxylin and eosin using standard methods, using the TUNEL assay (Gavrieli et al. 1992), with an antibody to BrdU (Caltag; Gratzner 1982) and with an antibody to PECAM-1 (Pharmingen; Vecchi et al. 1994).

\section{Acknowledgments}

We thank Martine Roussel for providing the ER/Myc vector, Gary P. Nolan for the Phoenix packaging cell line, and Ron Wisdom for the pBabe vectors. R.A.F. and R.J.D. are investigators with the Howard Hughes Medical Institute. These studies were supported by a grant from the National Cancer Institute.

The publication costs of this article were defrayed in part by payment of page charges. This article must therefore be hereby marked "advertisement" in accordance with 18 USC section 1734 solely to indicate this fact.

\section{References}

Behrens, A., Jochum, W., Sibilia, M., and Wagner, E.F. 2000. Oncogenic transformation by ras and fos is mediated by cJun N-terminal phosphorylation. Oncogene 19: 2657-2663.

Bennett, B.L., Sasaki, D.T., Murray, B.W., O'Leary, E.C., Sakata, S.T., Xu, W., Leisten, J.C., Motiwala, A., Pierce, S., Satoh, Y., et al. 2001. SP600125, an anthrapyrazolone inhibitor of Jun N-terminal kinase. Proc. Natl. Acad. Sci. 98: 13681-13686.

Bos, J.L. 1989. Ras oncogenes in human cancer: A review. Cancer Res. 49: 4682-4689.

Bost, F., McKay, R., Bost, M., Potapova, O., Dean, N.M., and Mercola, D. 1999. The Jun kinase 2 isoform is preferentially required for epidermal growth factor-induced transformation of human A549 lung carcinoma cells. Mol. Cell. Biol. 19: $1938-1949$.

Clark, G.J., Cox, A.D., Graham, S.M., and Der, C.J. 1995. Biological assays for Ras transformation. Methods Enzymol. 255: 395-412.

Danos, O. and Mulligan, R.C. 1988. Safe and efficient generation of recombinant retroviruses with amphotropic and ecotropic host ranges. Proc. Natl. Acad. Sci. 85: 6460-6464.

Datta, S.R., Brunet, A., and Greenberg, M.E. 1999. Cellular survival: A play in three Akts. Genes \& Dev. 13: 2905-2927.

Davis, R.J. 2000. Signal transduction by the JNK group of MAP kinases. Cell 103: 239-252.

Debies, M.T. and Welch, D.R. 2001. Genetic basis of human breast cancer metastasis. I. Mammary Gland Biol. Neoplasia. 6: 441-451.

Evan, G.I. and Vousden, K.H. 2001. Proliferation, cell cycle, and apoptosis in cancer. Nature 411: 342-348.

Ganiatsas, S., Kwee, L., Fujiwara, Y., Perkins, A., Ikeda, T., Labow, M.A., and Zon, L.I. 1998. SEK1 deficiency reveals mitogen-activated protein kinase cascade crossregulation 
and leads to abnormal hepatogenesis. Proc. Nat1. Acad. Sci. 95: 6881-6886.

Gavrieli, Y., Sherman, Y., and Ben-Sasson, S.A. 1992. Identification of programmed cell death in situ via specific labeling of nuclear DNA fragmentation. J. Cell Biol. 119: 493-501.

Gratzner, H.G. 1982. Monoclonal antibody to 5-bromo- and 5-iododeoxyuridine: A new reagent for detection of DNA replication. Science 218: 474-475.

Gross, A., McDonnell, J.M., and Korsmeyer, S.J. 1999. BCL-2 family members and the mitochondria in apoptosis. Genes \& Dev. 13: 1899-1911.

Harvey, M., Sands, A.T., Weiss, R.S., Hegi, M.E., Wiseman, R.W., Pantazis, P., Giovanella, B.C., Tainsky, M.A., Bradley, A., and Donehower, L.A. 1993. In vitro growth characteristics of embryo fibroblasts isolated from p53-deficient mice. Oncogene 8: 2457-2467.

Hess, P., Pihan, G., Sawyers, C.L., Flavell, R.A., and Davis, R.J. 2002. Survival signaling mediated by c-Jun $\mathrm{NH}(2)$-terminal kinase in transformed B lymphoblasts. Nat. Genet. 32: 201205.

Johnson, R., Spiegelman, B., Hanahan, D., and Wisdom, R. 1996. Cellular transformation and malignancy induced by ras require c-jun. Mol. Cell. Biol. 16: 4504-4511.

Joneson, T. and Bar-Sagi, D. 1999. Suppression of Ras-induced apoptosis by the Rac GTPase. Mol. Cell. Biol. 19: 5892-5901.

Kim, H.L., Griend, D.J., Yang, X., Benson, D.A., Dubauskas, Z., Yoshida, B.A., Chekmareva, M.A., Ichikawa, Y., Sokoloff, M.H., Zhan, P., et al. 2001. Mitogen-activated protein kinase kinase 4 metastasis suppressor gene expression is inversely related to histological pattern in advancing human prostatic cancers. Cancer Res. 61: 2833-2837.

Kuan, C.Y., Yang, D.D., Samanta Roy, D.R., Davis, R.J., Rakic, P., and Flavell, R.A. 1999. The Jnk1 and Jnk2 protein kinases are required for regional specific apoptosis during early brain development. Neuron 22: 667-676.

Macleod, K.F., Sherry, N., Hannon, G., Beach, D., Tokino, T., Kinzler, K., Vogelstein, B., and Jacks, T. 1995. p53-dependent and independent expression of p21 during cell growth, differentiation, and DNA damage. Genes \& Dev. 9: 935-944.

Maehama, T., Taylor, G.S., and Dixon, J.E. 2001. PTEN and myotubularin: Novel phosphoinositide phosphatases. Annu. Rev. Biochem. 70: 247-279.

Morgenstern, J.P. and Land, H. 1990. Advanced mammalian gene transfer: High titre retroviral vectors with multiple drug selection markers and a complementary helper-free packaging cell line. Nucleic Acids Res. 18: 3587-3596.

Nakano, K. and Vousden, K.H. 2001. PUMA, a novel proapoptotic gene, is induced by p53. Mol. Cell 7: 683-694.

Nishina, H., Fischer, K.D., Radvanyi, L., Shahinian, A., Hakem, R., Rubie, E.A., Bernstein, A., Mak, T.W., Woodgett, J.R., and Penninger, J.M. 1997. Stress-signalling kinase Sek1 protects thymocytes from apoptosis mediated by CD95 and CD3. Nature 385: 350-353.

Pear, W.S., Nolan, G.P., Scott, M.L., and Baltimore, D. 1993. Production of high-titer helper-free retroviruses by transient transfection. Proc. Natl. Acad. Sci. 90: 8392-8396.

Potapova, O., Haghighi, A., Bost, F., Liu, C., Birrer, M.J., Gjerset, R., and Mercola, D. 1997. The Jun kinase/stress-activated protein kinase pathway functions to regulate DNA repair and inhibition of the pathway sensitizes tumor cells to cisplatin. J. Biol. Chem. 272: 14041-14044.

Potapova, O., Gorospe, M., Bost, F., Dean, N.M., Gaarde, W.A., Mercola, D., and Holbrook, N.J. 2000. c-Jun N-terminal kinase is essential for growth of human T98G glioblastoma cells. J. Biol. Chem. 275: 24767-24775.

Raingeaud, J., Gupta, S., Rogers, J.S., Dickens, M., Han, J., Ulev- itch, R.J., and Davis, R.J. 1995. Pro-inflammatory cytokines and environmental stress cause p38 mitogen-activated protein kinase activation by dual phosphorylation on tyrosine and threonine. J. Biol. Chem. 270: 7420-7426.

Sabapathy, K., Jochum, W., Hochedlinger, K., Chang, L., Karin, M., and Wagner, E.F. 1999. Defective neural tube morphogenesis and altered apoptosis in the absence of both JNK1 and JNK2. Mech. Dev. 89: 115-124.

Sherr, C.J. and DePinho, R.A. 2000. Cellular senescence: Mitotic clock or culture shock? Cell 102: 407-410.

Soengas, M.S., Alarcon, R.M., Yoshida, H., Giaccia, A.J., Hakem, R., Mak, T.W., and Lowe, S.W. 1999. Apaf-1 and caspase-9 in p53-dependent apoptosis and tumor inhibition. Science 284: 156-159.

Soengas, M.S., Capodieci, P., Polsky, D., Mora, J., Esteller, M., Opitz-Araya, X., McCombie, R., Herman, J.G., Gerald, W.L., Lazebnik, Y.A., et al. 2001. Inactivation of the apoptosis effector Apaf-1 in malignant melanoma. Nature 409: 207-211.

Su, G.H., Hilgers, W., Shekher, M.C., Tang, D.J., Yeo, C.J., Hruban, R.H., and Kern, S.E. 1998. Alterations in pancreatic, biliary, and breast carcinomas support MKK4 as a genetically targeted tumor suppressor gene. Cancer Res. 58: 2339-2342.

Su, G.H., Song, J.J., Repasky, E.A., Schutte, M., and Kern, S.E. 2002. Mutation rate of MAP2K4/MKK4 in breast carcinoma. Hum. Mutat. 19: 81.

Teng, D.H., Perry III, W.L., Hogan, J.K., Baumgard, M., Bell, R., Berry, S., Davis, T., Frank, D., Frye, C., Hattier, T., et al. 1997. Human mitogen-activated protein kinase kinase 4 as a candidate tumor suppressor. Cancer Res. 57: 4177-4182.

Tournier, C., Hess, P., Yang, D.D., Xu, J., Turner, T.K., Nimnual, A., Bar-Sagi, D., Jones, S.N., Flavell, R.A., and Davis, R.J. 2000. Requirement of JNK for stress-induced activation of the cytochrome c-mediated death pathway. Science 288: $870-874$.

Tournier, C., Dong, C., Turner, T.K., Jones, S.N., Flavell, R.A., and Davis, R.J. 2001. MKK7 is an essential component of the JNK signal transduction pathway activated by proinflammatory cytokines. Genes \& Dev. 15: 1419-1426.

Vecchi, A., Garlanda, C., Lampugnani, M.G., Resnati, M., Matteucci, C., Stoppacciaro, A., Schnurch, H., Risau, W., Ruco, L., Mantovani, A., et al. 1994. Monoclonal antibodies specific for endothelial cells of mouse blood vessels. Their application in the identification of adult and embryonic endothelium. Eur. J. Cell Biol. 63: 247-254.

Vogelstein, B., Lane, D., and Levine, A.J. 2000. Surfing the p53 network. Nature 408: 307-310.

Wu, C.W., Li, A.F., Chi, C.W., Huang, C.L., Shen, K.H., Liu, W.Y., and Lin, W. 2000. Human gastric cancer kinase profile and prognostic significance of MKK4 kinase. Am. J. Pathol. 156: $2007-2015$

Yamada, S.D., Hickson, J.A., Hrobowski, Y., Vander Griend, D.J., Benson, D., Montag, A., Karrison, T., Huo, D., Rutgers, J., Adams, S., et al. 2002. Mitogen-activated protein kinase kinase 4 (MKK4) acts as a metastasis suppressor gene in human ovarian carcinoma. Cancer Res. 62: 6717-6723.

Yang, D., Tournier, C., Wysk, M., Lu, H.T., Xu, J., Davis, R.J., and Flavell, R.A. 1997a. Targeted disruption of the MKK4 gene causes embryonic death, inhibition of c-Jun NH2-terminal kinase activation, and defects in AP-1 transcriptional activity. Proc. Natl. Acad. Sci. 94: 3004-3009.

Yang, D.D., Kuan, C.Y., Whitmarsh, A.J., Rincon, M., Zheng, T.S., Davis, R.J., Rakic, P., and Flavell, R.A. 1997b. Absence of excitotoxicity-induced apoptosis in the hippocampus of mice lacking the Jnk3 gene. Nature 389: 865-870.

Yoshida, B.A., Dubauskas, Z., Chekmareva, M.A., Christiano, T.R., Stadler, W.M., and Rinker-Schaeffer, C.W. 1999. Mito- 
gen-activated protein kinase kinase 4/stress-activated protein/Erk kinase 1 (MKK4/SEK1), a prostate cancer metastasis suppressor gene encoded by human chromosome 17. Cancer Res. 59: 5483-5487.

Yoshida, S., Fukino, K., Harada, H., Nagai, H., Imoto, I., Inazawa, J., Takahashi, H., Teramoto, A., and Emi, M. 2001. The c-Jun NH2-terminal kinase3 (JNK3) gene: Genomic structure, chromosomal assignment, and loss of expression in brain tumors. J. Hum. Genet. 46: 182-187.

Yu, J., Zhang, L., Hwang, P.M., Kinzler, K.W., and Vogelstein, B. 2001. PUMA induces the rapid apoptosis of colorectal cancer cells. Mol. Cell 7: 673-682.

Zindy, F., Eischen, C.M., Randle, D.H., Kamijo, T., Cleveland, J.L., Sherr, C.J., and Roussel, M.F. 1998. Myc signaling via the ARF tumor suppressor regulates p53-dependent apoptosis and immortalization. Genes \& Dev. 12: 2424-2433.

Zong, W.X., Lindsten, T., Ross, A.J., MacGregor, G.R., and Thompson, C.B. 2001. BH3-only proteins that bind prosurvival Bcl-2 family members fail to induce apoptosis in the absence of Bax and Bak. Genes \& Dev. 15: 1481-1486. 


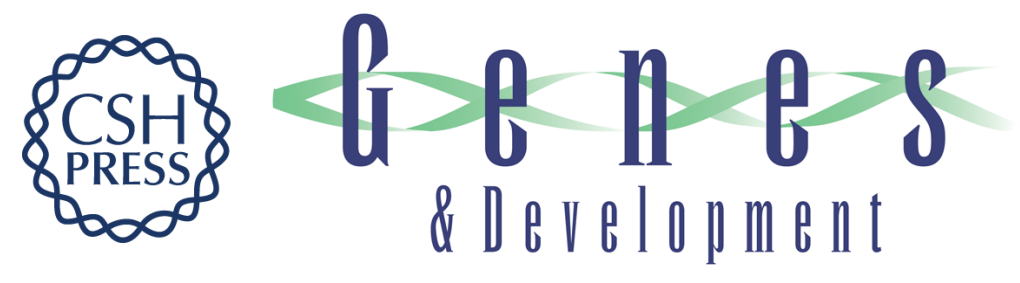

\section{Suppression of Ras-stimulated transformation by the JNK signal transduction pathway}

Norman J. Kennedy, Hayla K. Sluss, Stephen N. Jones, et al.

Genes Dev. 2003, 17:

Access the most recent version at doi:10.1101/gad.1062903

References This article cites 48 articles, 27 of which can be accessed free at: http://genesdev.cshlp.org/content/17/5/629.full.html\#ref-list-1

License

Email Alerting

Receive free email alerts when new articles cite this article - sign up in the box at the top Service right corner of the article or click here.

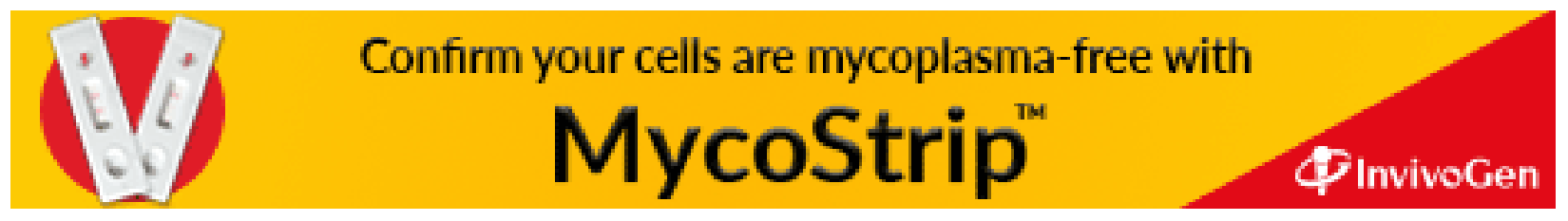

